\title{
Analysis of GNB Species and Pattern of Resistance Responsible for LRTI in Patients with Cancer
}

\author{
Salwa Selim Afifi ${ }^{1}$, Zeinab Helal Helal ${ }^{1,}$, , Safaa Shawky Hassan ${ }^{2}$, Sally Tohamy Kamal ${ }^{1}$ \\ ${ }^{1}$ Department of Microbiology and Immunology, Faculty of Pharmacy, Al-azhar University, Cairo, Egypt \\ ${ }^{2}$ Department of Clinical Pathology, National Cancer Institute, Cairo University, Cairo, Egypt
}

Email address:

prof.salwaafifi@yahoo.com (S. S. Afifi), zeinabhelal@hotmail.com (Z. H. Helal), safaa_shawky@hotmail.com (S. S. Hassan), dr_sallytohamy@yahoo.com (S. T. Kamal)

\section{To cite this article:}

Salwa Selim Afifi, Zeinab Helal Helal, Safaa Shawky Hassan, Sally Tohamy Kamal. Analysis of GNB Species and Pattern of Resistance Responsible for LRTI in Patients with Cancer. American Journal of Biomedical and Life Sciences. Vol. 3, No. 2, 2015, pp. 25-32. doi: $10.11648 /$ j.ajbls.20150302.13

\begin{abstract}
Lower respiratory tract infection (LRTI) is the most lethal infection remains among patients undergoing treatment for cancer. Most of the previous studies with cancer patients have focus on blood stream infections. For that reason the aim of our study was to examine the spectrum and recent trends in antimicrobial resistance of Gram negative bacteria (GNB) recovered from cancer patient having LRTI in Egypt. In addition our objective was to investigate the prevalence and distribution of Legionella pneumophila among cancer patients with LRTI. Sputum specimens were collected from 285 cancer patients suspecting of having LRTI. The conventional methods and Microscan Negative Identification panel Type 2 were used for identification of GNB. Susceptibility was assessed for 20 antibiotics in bacterial isolates using agar diffusion method. All the sputum specimens were tested by culture and genus specific PCR for the detection of Legionella pneumophila. A total of 130 GNB were isolated. Among these, Klebsiella pneumoniae was the most common (35.4\%). We isolated and identified a number of less frequent GNB (17\%), whereas no Legionella pneumophila was detected. Amikacin was found to be the most effective antimicrobial against GNB. We reported very high percentage of multi-drug resistance GNB (96\%). This study reported the development of multidrug resistance Gram negative bacilli in Egypt. Continuous updating of data on antimicrobial susceptibility profiles is required to ensure the efficacy of antimicrobial agents against GNB due to continuous development of antimicrobial resistance patterns among these pathogens.
\end{abstract}

Keywords: Lower Respiratory Tract Infection, Cancer Patients, Gram-Negative Bacteria, Legionella Pneumophila

\section{Introduction}

Immunocompromised term describes a host who is at increased risk for Life-threatening infection as a consequence of abnormality of the immune system. During the past few decades, the population of immunocompromised patients has developed hugely, blame on the increased use of immunosuppressive drugs [1].

The mortality rates in immunocompromised patients associated with Lower respiratory tract infection (LRTI) are reported between $12 \%$ and $50 \%$ and the progression from upper respiratory tract infection to LRTI in immunocompromised patients is estimated between $13 \%$ and $43 \%$ [2]. LRTI covers a wide spectrum of disease including pneumonia, acute bronchitis and aggravation of chronic lung disease [3].
Pneumonia is a recurrent complication in immunocompromised patients, including patients who have hematologic malignancies, have received cytotoxic therapy, or solid organ transplantation [4]. Patients with cancer are at increased risk for Gram negative pneumonia. In hospitalized patients, oropharynx becomes colonized with Gram negative bacilli that are more virulent than normal flora. Gram negative pathogens especially Pseudomonas aeruginosa $(P$. aeruginosa) and Klebsiella pneumoniae (K. pneumoniae) are predominant in the first three months, whereas, Gram positive bacteria cause most of the infection seen subsequently [5]. Legionella spp. has been reported to be an important cause of nosocomial pneumonia in some centers $[6,7]$. In addition, outbreaks of nosocomial legionellosis are a frequent problem in hospital environment [8]. Legionella species represent normal environmental flora, many cause human disease, most commonly opportunistic pneumonia in 
immunocompromised hosts. Approximately $85 \%$ of such cases are due to Legionella pneumophila $[9,10]$. Legionella pneumonia can be subclinical or severe and life threatening. The fatality rate can move toward $50 \%$ in immunocompromised hosts [11].

In general, infections that are caused by multi-drug resistant Gram negative bacteria (GNB) are associated with up to five times higher mortality rates compared with infections that are caused by susceptible GNB [12, 13]. In addition, infections with multi-drug resistance GNB lead to less desirable outcomes, including longer hospital stays and utmost cost of hospitalization [12].

In the present study, both patients with hematologic malignancies and patients with solid tumors were included. The aim of the study was to search the distribution and antimicrobial resistance of aerobic GNB causing LRTI among cancer patients in Egypt. The study was not limited to the most common GNB, but included less frequent GNB as well. Also the study was done to obtain the insight of the prevalence and distribution of Legionella pneumophila among cancer patients in Egypt.

\section{Methodology}

\subsection{Study Specimens Collection}

The study was carried out at Microbiology Laboratory of National Cancer Institute, Cairo University, Cairo, Egypt, and Microbiology Laboratory of Faculty of Pharmacy, Alazhar University, Cairo, Egypt, over a period from December 2012 to July 2014. All hospitalized cancer patients undergoing anti-cancer therapy, with suspected LRTI, were studied. No discrimination was made on the basis of age or gender. A total of 285 sputum specimens were collected, which were submitted to the Microbiology Laboratory of National Cancer Institute (NCI) Cairo, Egypt, for routine culture.

\subsection{Isolation and Identification of $G N B$}

Aerobic GNB were isolated and identified using standard methods and biochemical tests [14]. Microscan Negative Identification panel Type 2 (DadeBehring, West Sacramento, USA) was used to confirm the identification of Gram negative isolates. Microscan negative identification panel Type 2, is an in vitro diagnostic method that uses fluorescence technology to detect bacterial growth or metabolic activity and can automatically identify Gram negative bacteria to species level. The system is based upon the reaction obtained with 34 biochemical test dosed and dried into Microscan panel.

\subsection{Growth Conditions of Legionella}

Reference strains of Legionella pneumophila ATCC $®$ 33152 and sputum specimens, washed with a $0.2 \mathrm{M} \mathrm{KCl-HCl}$ solution, $\mathrm{pH} 2.2$ [15], were cultured on buffered charcoal yeast extract (BCYE) agar supplemented with $\alpha$ ketoglutarate. This medium provides iron and L-cysteine, both of which are essential for the growth of legionellae [16].

\subsection{Antimicrobial Susceptibility Determination}

All aerobic GNB isolates were tested for antibiotic susceptibility by the disk diffusion method described by Kirby Bauer according to the Clinical Laboratory Standard Institute [17]. The antibiotic panel included: Amikacin (30 $\mu \mathrm{g})$, Ampicillin $(10 \mu \mathrm{g})$, Amoxicillin /Clavulanic acid $(20 \mu \mathrm{g} /$ $10 \mu \mathrm{g})$, Ampicillin/Sulbactam $(20 \mu \mathrm{g} / 10 \mu \mathrm{g})$, Aztreonam (30 $\mu \mathrm{g})$, Ceftazidime $(30 \mu \mathrm{g})$, Ciprofloxacin $(5 \mu \mathrm{g})$, Cefoxitin (30 $\mu \mathrm{g})$, Ceftriaxone $(30 \mu \mathrm{g})$, Cefotaxime $(30 \mu \mathrm{g})$, Gentamicin $(10 \mu \mathrm{g})$, Imipenem $(10 \mu \mathrm{g})$, Levofloxacin $(5 \mu \mathrm{g})$, Meropenem $(10 \mu \mathrm{g})$, Trimethoprim /Sulfamethoxazole (Co-trimoxazole) (300 $\mu \mathrm{g} / 25 \mu \mathrm{g})$, Piperacillin $(10 \mu \mathrm{g})$, Tobramycin $(10 \mu \mathrm{g})$, Piperacillin/Tazobactam $(100 \mu \mathrm{g} / 10 \mu \mathrm{g})$, Tetracycline $(30 \mu \mathrm{g})$ and Tigecyclin $(15 \mu \mathrm{g})$ (Oxoid ltd., Basin Stoke, Hants, England). Resistance to each antibiotic was recorded and the strains resistant to one antimicrobial agent in the three or more antimicrobial categories were defined as multi-drug resistant [18].

\subsection{DNA isolation and PCR for Legionella}

DNAs from clinical specimens and reference strains of Legionella pneumophila were extracted using the QIAamp ${ }^{\circledR}$ DNA Mini Kit (Qiagen, USA) according to the manufacture manuals.

For each DNA sample PCR reaction was performed using forward (5' - GCT TAA CCT GGG ACG GTC AGA T - 3') and reverse (5' -GCG CCA CTA ATT ATT TTC ATA TAA- 3') oligonucleotides specific primer for Legionella pneumophila described previously [19] which amplify 245bp fragments. Primers were prepared by Vivantis, Malaysia. For PCR, Dream Taq Green Master Mix (Thermo scientific, EU) was used. Amplification reactions were performed in a volume of $50 \mu \mathrm{l}$ with final amounts of $25 \mu \mathrm{l}$ of Dream Taq Green Master Mix, $0.5 \mu \mathrm{M}$ of each primer and 500ng of extracted DNA.The thermal cycles were as followed: the reaction mixtures were incubated for $5 \mathrm{~min}$ at $94^{\circ} \mathrm{C}$ for denaturation; 40 cycles of $1 \mathrm{~min}$ at $94^{\circ} \mathrm{C} ; 1 \mathrm{~min}$ at $53^{\circ} \mathrm{C}$ and $2 \mathrm{~min}$ at $72^{\circ} \mathrm{C}$ and finally $5 \mathrm{~min}$ at $72^{\circ} \mathrm{C}$. The PCR products were detected by electrophoresis on $2 \%$ agarose gel.

\section{Results}

In the present study, a total of 130 aerobic Gram negative bacilli were recovered from sputum specimens. All the isolates were identified conventionally and by using semiautomated systems. The main isolated Gram negative bacilli were $K$. pneumoniae (35.4\%) followed by Escherichia coli (E. coli) (20\%), Acinetobacter baumannii (A. baumannii) (17\%) then P. aeruginosa (10.3\%) (Table1).

In the present study, patients were classified into two groups; those with hematological malignancies and those with solid organ malignancies. Out of 130 Gram negative isolates, $77(59 \%)$ isolates were obtained from hematologic malignancies patients, whereas only $53(41 \%)$ isolates were 
obtained from solid tumor patients (Table1).

In both hematologic malignancies and solid tumor patients, Gram negative bacteria were mainly $K$. pneumoniae $(20 \%$ among hematologic malignancies patients and $15.4 \%$ among solid-tumor cancer patients) (Table1).

Regarding the detection of Legionella pneumophila by culture and PCR, all sputum specimens were negative.

The antimicrobial activity of penicillin derivatives, cephalosporins, monobactams, carbapenems, tetracyclines, quinolones, and aminoglycosides group of antimicrobial agents against aerobic Gram negative bacilli isolated from LRTI of cancer patients is shown (Tables 2 and 3). We reported resistance rates of GNB as $68.5 \%$ - 99.2\% against penicillin derivatives, $89.2 \%$ against monobactam, $46.2 \%$ $51.5 \%$ against carbapenems, $79.2 \%$ - 95.4\% against cephalosporins, $42.3 \%$ - 79.2\% against aminoglycosides, $65.4 \%$ - $68.5 \%$ against quinolones and $83 \%$ against Cotrimoxazole.

Among all the antimicrobials used, amikacin, imipenem and meropenem showed highest activity against E.coli, $K$. pneumoniae and P.aeruginosa strains. Among quinolones, levofloxacin has the highest activity. Gentamicin was also found to be effective against Acinetobacter baumannii isolates.

Chromobacterium violaceum and Chryseobacterium meningosepticum were resistance to all antimicrobial agents used.

In current study, 96\% (125/130) of isolated Gram negative bacilli were multi-drug resistant.

\section{Discussion}

Lower respiratory tract infection complications are a serious cause of morbidity and mortality in cancer patients, especially those with hematological malignancies [20, 21]. By different ways, chemotherapeutic agents predispose bacterial infection [22]. Many of these agents damage the body's immune system [23].

Reemergence of Gram negative infections and increased antimicrobial resistance due to overuse of antibiotics in cancer patients have changed the epidemiology of bacterial infections among these patients $[24,25]$.

Table 1. Spectrum of Gram negative bacteria among cancer patients with LRTI.

\begin{tabular}{|c|c|c|c|}
\hline \multirow{2}{*}{ Types of Gram negative bacilli } & Patients with hematological malignancies & Patients with solid tumor & Total \\
\hline & N (\%) & N (\%) & $\mathbf{N}(\%)$ \\
\hline \multicolumn{4}{|l|}{ Enterobacteriaceae } \\
\hline Escherichia coli & $9(7)$ & $17(13)$ & $26(20)$ \\
\hline Escherichia vulneris & $1(0.8)$ & $0(0)$ & $1(0.8)$ \\
\hline Klebsiella pneumoniae & $26(20)$ & $20(15.4)$ & $46(35.4)$ \\
\hline Klebsiella ozaenae & $1(0.8)$ & $0(0)$ & $1(0.8)$ \\
\hline Serratia marcescens & $1(0.8)$ & $2(1.5)$ & $3(2.3)$ \\
\hline Enterobacter cloacae & $1(0.8)$ & $1(0.8)$ & $2(1.6)$ \\
\hline Enterobacter aerogenes & $2(1.6)$ & $0(0)$ & $2(1.6)$ \\
\hline Citrobacter freundil & $2(1.6)$ & $0(0)$ & $2(1.6)$ \\
\hline Providencia stuartii & $1(0.8)$ & $0(0)$ & $1(0.8)$ \\
\hline \multicolumn{4}{|l|}{ Non fermentative Gram negative bacilli } \\
\hline Acinetobacter baumannii & $12(9)$ & $10(8)$ & $(17) 22$ \\
\hline Acinetobacter haemolyticus & $1(0.8)$ & $0(0)$ & $1(0.8)$ \\
\hline Pseudomonas aeruginosa & $11(8)$ & $3(2.3)$ & $14(10.3)$ \\
\hline Pseudomonas fluorescens & $1(0.8)$ & $0(0)$ & $1(0.8)$ \\
\hline Pseudomonas oryzihabitans & $1(0.8)$ & $0(0)$ & $1(0.8)$ \\
\hline Stenotrophomonas maltophilia & $4(3)$ & $0(0)$ & $4(3)$ \\
\hline Burkholderia cepacia & $1(0.8)$ & $0(0)$ & $1(0.8)$ \\
\hline \multicolumn{4}{|l|}{ Other Gram negative bacteria } \\
\hline Chromobacterium violaceum & $1(0.8)$ & $0(0)$ & $1(0.8)$ \\
\hline Chryseobacterium meningosepticum & $1(0.8)$ & $0(0)$ & $1(0.8)$ \\
\hline Total & $77(59)$ & $53(41)$ & 130 \\
\hline
\end{tabular}


Table 2. Antibiotic susceptibility pattern of Enterobacteriaceae.

\begin{tabular}{|c|c|c|c|c|c|c|c|c|c|c|c|c|c|c|c|c|c|c|}
\hline \multirow[b]{2}{*}{ AB } & \multicolumn{2}{|c|}{$\begin{array}{l}\text { Escherichia } \\
\text { coli }\end{array}$} & \multicolumn{2}{|c|}{$\begin{array}{l}\text { Escherichia } \\
\text { vulneris }\end{array}$} & \multicolumn{2}{|c|}{$\begin{array}{l}\text { Klebsiella } \\
\text { pneumoniae }\end{array}$} & \multicolumn{2}{|c|}{$\begin{array}{l}\text { Klebsiella } \\
\text { ozaenae }\end{array}$} & \multicolumn{2}{|c|}{$\begin{array}{l}\text { Serratia } \\
\text { marcescens }\end{array}$} & \multicolumn{2}{|c|}{$\begin{array}{l}\text { Enterobacter } \\
\text { cloacae }\end{array}$} & \multicolumn{2}{|c|}{$\begin{array}{l}\text { Enterobacter } \\
\text { aerogenes }\end{array}$} & \multicolumn{2}{|c|}{$\begin{array}{l}\text { Citrobacter } \\
\text { freundil }\end{array}$} & \multicolumn{2}{|c|}{$\begin{array}{l}\text { Providencia } \\
\text { stuartii }\end{array}$} \\
\hline & $\begin{array}{l}\text { S } \\
\text { n } \\
(\%)\end{array}$ & $\begin{array}{l}\text { R } \\
n \\
(\%)\end{array}$ & $\begin{array}{l}\text { S } \\
\text { n } \\
(\%)\end{array}$ & $\begin{array}{l}\text { R } \\
n \\
(\%)\end{array}$ & $\begin{array}{l}\text { S } \\
\text { n } \\
(\%)\end{array}$ & $\begin{array}{l}\text { R } \\
\mathrm{n} \\
(\%)\end{array}$ & $\begin{array}{l}\text { S } \\
\mathrm{n} \\
(\%)\end{array}$ & $\begin{array}{l}\mathrm{R} \\
\mathrm{n} \\
(\%)\end{array}$ & $\begin{array}{l}\text { S } \\
\text { n } \\
(\%)\end{array}$ & $\begin{array}{l}\text { R } \\
n \\
(\%)\end{array}$ & $\begin{array}{l}\text { S } \\
\text { n } \\
(\%)\end{array}$ & $\begin{array}{l}\text { R } \\
\mathrm{n} \\
(\%)\end{array}$ & $\begin{array}{l}\text { S } \\
\text { n } \\
(\%)\end{array}$ & $\begin{array}{l}\text { R } \\
\text { n } \\
(\%)\end{array}$ & $\begin{array}{l}\text { S } \\
\text { n } \\
(\%)\end{array}$ & $\begin{array}{l}\text { R } \\
\text { n } \\
(\%)\end{array}$ & $\begin{array}{l}\text { S } \\
\text { n } \\
(\%)\end{array}$ & $\begin{array}{l}\text { R } \\
\mathrm{n} \\
(\%)\end{array}$ \\
\hline Ampicillin & $\begin{array}{l}0 \\
(0)\end{array}$ & $\begin{array}{l}26 \\
(100)\end{array}$ & $\begin{array}{l}0 \\
(0)\end{array}$ & $\begin{array}{l}1 \\
(100)\end{array}$ & $\begin{array}{l}0 \\
(0)\end{array}$ & $\begin{array}{l}46 \\
(100)\end{array}$ & $\begin{array}{l}1 \\
(100)\end{array}$ & $\begin{array}{l}0 \\
(0)\end{array}$ & $\begin{array}{l}0 \\
(0)\end{array}$ & $\begin{array}{l}3 \\
(100)\end{array}$ & $\begin{array}{l}0 \\
(0)\end{array}$ & $\begin{array}{l}2 \\
(100)\end{array}$ & $\begin{array}{l}0 \\
(0)\end{array}$ & $\begin{array}{l}2 \\
(100)\end{array}$ & $\begin{array}{l}0 \\
(0)\end{array}$ & $\begin{array}{l}2 \\
(100)\end{array}$ & $\begin{array}{l}0 \\
(0)\end{array}$ & $\begin{array}{l}1 \\
(100)\end{array}$ \\
\hline $\begin{array}{l}\text { Amoxicillin/ } \\
\text { Clavulanic acid }\end{array}$ & $\begin{array}{l}2 \\
(8)\end{array}$ & $\begin{array}{l}24 \\
(92)\end{array}$ & $\begin{array}{l}1 \\
(100)\end{array}$ & $\begin{array}{l}0 \\
(0)\end{array}$ & $\begin{array}{l}8 \\
(17)\end{array}$ & $\begin{array}{l}38 \\
(83)\end{array}$ & $\begin{array}{l}1 \\
(100)\end{array}$ & $\begin{array}{l}0 \\
(0)\end{array}$ & $\begin{array}{l}1 \\
(33)\end{array}$ & $\begin{array}{l}2 \\
(67)\end{array}$ & $\begin{array}{l}1 \\
(50)\end{array}$ & $\begin{array}{l}1 \\
(50)\end{array}$ & $\begin{array}{l}0 \\
(0)\end{array}$ & $\begin{array}{l}2 \\
(100)\end{array}$ & $\begin{array}{l}0 \\
(0)\end{array}$ & $\begin{array}{l}2 \\
(100)\end{array}$ & $\begin{array}{l}0 \\
(0)\end{array}$ & $\begin{array}{l}1 \\
(100)\end{array}$ \\
\hline $\begin{array}{l}\text { Ampicillin/ } \\
\text { Sulbactam }\end{array}$ & $\begin{array}{l}0 \\
(0\end{array}$ & $\begin{array}{l}26 \\
(100)\end{array}$ & $\begin{array}{l}0 \\
(0)\end{array}$ & $\begin{array}{l}1 \\
(100)\end{array}$ & $\begin{array}{l}2 \\
(4)\end{array}$ & $\begin{array}{l}44 \\
(96)\end{array}$ & $\begin{array}{l}1 \\
(100)\end{array}$ & $\begin{array}{l}0 \\
(0)\end{array}$ & $\begin{array}{l}0 \\
(0)\end{array}$ & $\begin{array}{l}3 \\
(100)\end{array}$ & $\begin{array}{l}0 \\
(0)\end{array}$ & $\begin{array}{l}2 \\
(100)\end{array}$ & $\begin{array}{l}0 \\
(0)\end{array}$ & $\begin{array}{l}2 \\
(100)\end{array}$ & $\begin{array}{l}0 \\
(0)\end{array}$ & $\begin{array}{l}2 \\
(100)\end{array}$ & $\begin{array}{l}0 \\
(0)\end{array}$ & $\begin{array}{l}1 \\
(100)\end{array}$ \\
\hline $\begin{array}{l}\text { Piperacillin/ } \\
\text { Tazobactam }\end{array}$ & $\begin{array}{l}9 \\
(35)\end{array}$ & $\begin{array}{l}17 \\
(65)\end{array}$ & $\begin{array}{l}1 \\
(100)\end{array}$ & $\begin{array}{l}0 \\
(0)\end{array}$ & $\begin{array}{l}19 \\
(41)\end{array}$ & $\begin{array}{l}27 \\
(59)\end{array}$ & $\begin{array}{l}1 \\
(100)\end{array}$ & $\begin{array}{l}0 \\
(0)\end{array}$ & $\begin{array}{l}1 \\
(33)\end{array}$ & $\begin{array}{l}2 \\
(67)\end{array}$ & $\begin{array}{l}0 \\
(0)\end{array}$ & $\begin{array}{l}2 \\
(100)\end{array}$ & $\begin{array}{l}1 \\
(50)\end{array}$ & $\begin{array}{l}1 \\
(50)\end{array}$ & $\begin{array}{l}0 \\
(0)\end{array}$ & $\begin{array}{l}2 \\
(100)\end{array}$ & $\begin{array}{l}0 \\
(0)\end{array}$ & $\begin{array}{l}1 \\
(100)\end{array}$ \\
\hline Piperacillin & $\begin{array}{l}0 \\
(0)\end{array}$ & $\begin{array}{l}26 \\
(100)\end{array}$ & $\begin{array}{l}0 \\
(0)\end{array}$ & $\begin{array}{l}1 \\
(100)\end{array}$ & $\begin{array}{l}0 \\
(0)\end{array}$ & $\begin{array}{l}46 \\
(100)\end{array}$ & $\begin{array}{l}1 \\
(100)\end{array}$ & $\begin{array}{l}0 \\
(0)\end{array}$ & $\begin{array}{l}0 \\
(0)\end{array}$ & $\begin{array}{l}3 \\
(100)\end{array}$ & $\begin{array}{l}1 \\
(50)\end{array}$ & $\begin{array}{l}1 \\
(50)\end{array}$ & $\begin{array}{l}0 \\
(0)\end{array}$ & $\begin{array}{l}2 \\
(100)\end{array}$ & $\begin{array}{l}0 \\
(0)\end{array}$ & $\begin{array}{l}2 \\
(100)\end{array}$ & $\begin{array}{l}0 \\
(0)\end{array}$ & $\begin{array}{l}1 \\
(100)\end{array}$ \\
\hline Azteronam & $\begin{array}{l}1 \\
\text { (4) }\end{array}$ & $\begin{array}{l}25 \\
(96)\end{array}$ & $\begin{array}{l}0 \\
(0)\end{array}$ & $\begin{array}{l}1 \\
(100)\end{array}$ & $\begin{array}{l}6 \\
(13)\end{array}$ & $\begin{array}{l}40 \\
(87)\end{array}$ & $\begin{array}{l}1 \\
(100)\end{array}$ & $\begin{array}{l}0 \\
(0)\end{array}$ & $\begin{array}{l}2 \\
(67)\end{array}$ & $\begin{array}{l}1 \\
\text { (33) }\end{array}$ & $\begin{array}{l}1 \\
(50)\end{array}$ & $\begin{array}{l}1 \\
(50)\end{array}$ & $\begin{array}{l}0 \\
(0)\end{array}$ & $\begin{array}{l}2 \\
(100)\end{array}$ & $\begin{array}{l}0 \\
(0)\end{array}$ & $\begin{array}{l}2 \\
(100)\end{array}$ & $\begin{array}{l}0 \\
(0)\end{array}$ & $\begin{array}{l}1 \\
(100)\end{array}$ \\
\hline Meropenem & $\begin{array}{l}17 \\
(65)\end{array}$ & $\begin{array}{l}9 \\
(35)\end{array}$ & $\begin{array}{l}1 \\
(100)\end{array}$ & $\begin{array}{l}0 \\
(0)\end{array}$ & $\begin{array}{l}27 \\
(59)\end{array}$ & $\begin{array}{l}19 \\
(41)\end{array}$ & $\begin{array}{l}1 \\
(100)\end{array}$ & $\begin{array}{l}0 \\
(0)\end{array}$ & $\begin{array}{l}2 \\
(67)\end{array}$ & $\begin{array}{l}1 \\
\text { (33) }\end{array}$ & $\begin{array}{l}2 \\
(100)\end{array}$ & $\begin{array}{l}0 \\
(0)\end{array}$ & $\begin{array}{l}1 \\
(50)\end{array}$ & $\begin{array}{l}1 \\
(50)\end{array}$ & $\begin{array}{l}2 \\
(100)\end{array}$ & $\begin{array}{l}0 \\
(0)\end{array}$ & $\begin{array}{l}0 \\
(0)\end{array}$ & $\begin{array}{l}1 \\
(100)\end{array}$ \\
\hline Imipenem & $\begin{array}{l}20 \\
(77)\end{array}$ & $\begin{array}{l}6 \\
(23)\end{array}$ & $\begin{array}{l}1 \\
(100)\end{array}$ & $\begin{array}{l}0 \\
(0)\end{array}$ & $\begin{array}{l}28 \\
(61)\end{array}$ & $\begin{array}{l}18 \\
(39)\end{array}$ & $\begin{array}{l}1 \\
(100)\end{array}$ & $\begin{array}{l}0 \\
(0)\end{array}$ & $\begin{array}{l}3 \\
(100)\end{array}$ & $\begin{array}{l}0 \\
(0)\end{array}$ & $\begin{array}{l}2 \\
(100)\end{array}$ & $\begin{array}{l}0 \\
(0)\end{array}$ & $\begin{array}{l}1 \\
(50)\end{array}$ & $\begin{array}{l}1 \\
(50)\end{array}$ & $\begin{array}{l}1 \\
(50)\end{array}$ & $\begin{array}{l}1 \\
(50)\end{array}$ & $\begin{array}{l}0 \\
(0)\end{array}$ & $\begin{array}{l}1 \\
(100)\end{array}$ \\
\hline Cefoxitin & $\begin{array}{l}10 \\
(38.5)\end{array}$ & $\begin{array}{l}16 \\
(61.5)\end{array}$ & $\begin{array}{l}0 \\
(0)\end{array}$ & $\begin{array}{l}1 \\
(100)\end{array}$ & $\begin{array}{l}13 \\
(28)\end{array}$ & $\begin{array}{l}33 \\
(72)\end{array}$ & $\begin{array}{l}1 \\
(100)\end{array}$ & $\begin{array}{l}0 \\
(0)\end{array}$ & $\begin{array}{l}1 \\
(33)\end{array}$ & $\begin{array}{l}2 \\
(67)\end{array}$ & $\begin{array}{l}0 \\
(0)\end{array}$ & $\begin{array}{l}2 \\
(100)\end{array}$ & $\begin{array}{l}1 \\
(50)\end{array}$ & $\begin{array}{l}1 \\
(50)\end{array}$ & $\begin{array}{l}0 \\
(0)\end{array}$ & $\begin{array}{l}2 \\
(100)\end{array}$ & $\begin{array}{l}0 \\
(0)\end{array}$ & $\begin{array}{l}1 \\
(100)\end{array}$ \\
\hline Ceftazidim & $\begin{array}{l}1 \\
\text { (4) }\end{array}$ & $\begin{array}{l}25 \\
(96)\end{array}$ & $\begin{array}{l}0 \\
(0)\end{array}$ & $\begin{array}{l}1 \\
(100)\end{array}$ & $\begin{array}{l}7 \\
(15\end{array}$ & $\begin{array}{l}39 \\
(85)\end{array}$ & $\begin{array}{l}0 \\
(0)\end{array}$ & & $\begin{array}{l}0 \\
(0)\end{array}$ & $\begin{array}{l}3 \\
(100)\end{array}$ & $\begin{array}{l}1 \\
(50)\end{array}$ & $\begin{array}{l}1 \\
(50)\end{array}$ & $\begin{array}{l}0 \\
(0)\end{array}$ & & $\begin{array}{l}0 \\
(0)\end{array}$ & & $\begin{array}{l}0 \\
(0)\end{array}$ & $\begin{array}{l}1 \\
(100)\end{array}$ \\
\hline Cefotaxime & $\begin{array}{l}2 \\
(8)\end{array}$ & $\begin{array}{l}24 \\
(92)\end{array}$ & $\begin{array}{l}0 \\
(0)\end{array}$ & $\begin{array}{l}1 \\
(100)\end{array}$ & $\begin{array}{l}9 \\
(20)\end{array}$ & $\begin{array}{l}37 \\
(80)\end{array}$ & $\begin{array}{l}0 \\
(0)\end{array}$ & $\begin{array}{l}1 \\
(100)\end{array}$ & $\begin{array}{l}2 \\
(67)\end{array}$ & $\begin{array}{l}1 \\
\text { (33) }\end{array}$ & $\begin{array}{l}1 \\
(50)\end{array}$ & $\begin{array}{l}1 \\
(50)\end{array}$ & $\begin{array}{l}0 \\
(0)\end{array}$ & $\begin{array}{l}2 \\
(100)\end{array}$ & $\begin{array}{l}0 \\
(0)\end{array}$ & $\begin{array}{l}2 \\
(100)\end{array}$ & $\begin{array}{l}0 \\
(0)\end{array}$ & $\begin{array}{l}1 \\
(100)\end{array}$ \\
\hline Ceftriaxone & $\begin{array}{l}1 \\
\text { (4) }\end{array}$ & $\begin{array}{l}25 \\
(96)\end{array}$ & $\begin{array}{l}0 \\
(0)\end{array}$ & $\begin{array}{l}1 \\
(100)\end{array}$ & $\begin{array}{l}3 \\
(6.5)\end{array}$ & $\begin{array}{l}43 \\
(93.5)\end{array}$ & $\begin{array}{l}0 \\
(0)\end{array}$ & $\begin{array}{l}1 \\
(100)\end{array}$ & $\begin{array}{l}0 \\
(0)\end{array}$ & $\begin{array}{l}3 \\
(100)\end{array}$ & $\begin{array}{l}1 \\
(50)\end{array}$ & $\begin{array}{l}1 \\
(50)\end{array}$ & $\begin{array}{l}0 \\
(0)\end{array}$ & $\begin{array}{l}2 \\
(100)\end{array}$ & $\begin{array}{l}0 \\
(0)\end{array}$ & $\begin{array}{l}2 \\
(100)\end{array}$ & $\begin{array}{l}0 \\
(0)\end{array}$ & $\begin{array}{l}1 \\
(100)\end{array}$ \\
\hline Amikacin & $\begin{array}{l}20 \\
(77)\end{array}$ & $\begin{array}{l}6 \\
(23)\end{array}$ & $\begin{array}{l}1 \\
(100)\end{array}$ & $\begin{array}{l}0 \\
(0)\end{array}$ & $\begin{array}{l}32 \\
(70)\end{array}$ & $\begin{array}{l}14 \\
(30)\end{array}$ & $\begin{array}{l}1 \\
(100)\end{array}$ & $\begin{array}{l}0 \\
(0)\end{array}$ & $\begin{array}{l}2 \\
(67)\end{array}$ & $\begin{array}{l}1 \\
(33)\end{array}$ & $\begin{array}{l}2 \\
(100)\end{array}$ & $\begin{array}{l}0 \\
(0)\end{array}$ & $\begin{array}{l}1 \\
(50)\end{array}$ & $\begin{array}{l}1 \\
(50)\end{array}$ & $\begin{array}{l}2 \\
(100)\end{array}$ & $\begin{array}{l}0 \\
(0)\end{array}$ & $\begin{array}{l}0 \\
(0)\end{array}$ & $\begin{array}{l}1 \\
(100)\end{array}$ \\
\hline Gentamicin & $\begin{array}{l}12 \\
(46)\end{array}$ & $\begin{array}{l}14 \\
(54)\end{array}$ & $\begin{array}{l}0 \\
(0)\end{array}$ & $\begin{array}{l}1 \\
(100)\end{array}$ & $\begin{array}{l}12 \\
(26)\end{array}$ & $\begin{array}{l}34 \\
(74)\end{array}$ & $\begin{array}{l}1 \\
(100)\end{array}$ & $\begin{array}{l}0 \\
(0)\end{array}$ & $\begin{array}{l}2 \\
(67)\end{array}$ & $\begin{array}{l}1 \\
\text { (33) }\end{array}$ & $\begin{array}{l}2 \\
(100)\end{array}$ & $\begin{array}{l}0 \\
(0)\end{array}$ & $\begin{array}{l}0 \\
(0)\end{array}$ & $\begin{array}{l}2 \\
(100)\end{array}$ & $\begin{array}{l}2 \\
(100)\end{array}$ & $\begin{array}{l}0 \\
(0)\end{array}$ & $\begin{array}{l}0 \\
(0)\end{array}$ & $\begin{array}{l}1 \\
(100)\end{array}$ \\
\hline Tobramycin & $\begin{array}{l}6 \\
(23)\end{array}$ & $\begin{array}{l}20 \\
(77)\end{array}$ & $\begin{array}{l}0 \\
(0)\end{array}$ & $\begin{array}{l}1 \\
(100)\end{array}$ & $\begin{array}{l}9 \\
(20)\end{array}$ & $\begin{array}{l}37 \\
(80)\end{array}$ & $\begin{array}{l}0 \\
(0)\end{array}$ & $\begin{array}{l}1 \\
(100)\end{array}$ & $\begin{array}{l}1 \\
\text { (33) }\end{array}$ & $\begin{array}{l}2 \\
(67)\end{array}$ & $\begin{array}{l}2 \\
(100)\end{array}$ & $\begin{array}{l}0 \\
(0)\end{array}$ & $\begin{array}{l}0 \\
(0)\end{array}$ & $\begin{array}{l}2 \\
(100)\end{array}$ & $\begin{array}{l}0 \\
(0)\end{array}$ & $\begin{array}{l}2 \\
(100)\end{array}$ & $\begin{array}{l}0 \\
(0)\end{array}$ & $\begin{array}{l}1 \\
(100)\end{array}$ \\
\hline Tetracycline & $\begin{array}{l}3 \\
(11.5)\end{array}$ & $\begin{array}{l}23 \\
(88.5)\end{array}$ & $\begin{array}{l}0 \\
(0)\end{array}$ & $\begin{array}{l}1 \\
(100)\end{array}$ & $\begin{array}{l}4 \\
(9)\end{array}$ & $\begin{array}{l}42 \\
(91)\end{array}$ & $\begin{array}{l}1 \\
(100)\end{array}$ & $\begin{array}{l}0 \\
(0)\end{array}$ & $\begin{array}{l}0 \\
(0)\end{array}$ & $\begin{array}{l}3 \\
(100)\end{array}$ & $\begin{array}{l}1 \\
(50)\end{array}$ & $\begin{array}{l}1 \\
(50)\end{array}$ & $\begin{array}{l}0 \\
(0)\end{array}$ & $\begin{array}{l}2 \\
(100)\end{array}$ & $\begin{array}{l}0 \\
(0)\end{array}$ & $\begin{array}{l}2 \\
(100)\end{array}$ & $\begin{array}{l}0 \\
(0)\end{array}$ & $\begin{array}{l}1 \\
(100)\end{array}$ \\
\hline Tygacil & $\begin{array}{l}11 \\
(42)\end{array}$ & $\begin{array}{l}15 \\
(58)\end{array}$ & $\begin{array}{l}1 \\
(100)\end{array}$ & $\begin{array}{l}0 \\
(0)\end{array}$ & $\begin{array}{l}24 \\
(52)\end{array}$ & $\begin{array}{l}22 \\
(48)\end{array}$ & $\begin{array}{l}1 \\
(100)\end{array}$ & $\begin{array}{l}0 \\
(0)\end{array}$ & $\begin{array}{l}1 \\
\text { (33) }\end{array}$ & $\begin{array}{l}2 \\
(67)\end{array}$ & $\begin{array}{l}1 \\
(50)\end{array}$ & $\begin{array}{l}1 \\
(50)\end{array}$ & $\begin{array}{l}2 \\
(100)\end{array}$ & $\begin{array}{l}0 \\
(0)\end{array}$ & $\begin{array}{l}2 \\
(100)\end{array}$ & $\begin{array}{l}0 \\
(0)\end{array}$ & $\begin{array}{l}1 \\
(100)\end{array}$ & $\begin{array}{l}0 \\
(0)\end{array}$ \\
\hline Ciprofloxacin & $\begin{array}{l}6 \\
(23)\end{array}$ & $\begin{array}{l}20 \\
(77)\end{array}$ & $\begin{array}{l}0 \\
(0)\end{array}$ & $\begin{array}{l}1 \\
(100)\end{array}$ & $\begin{array}{l}17 \\
(37)\end{array}$ & $\begin{array}{l}29 \\
(63)\end{array}$ & $\begin{array}{l}1 \\
(100)\end{array}$ & $\begin{array}{l}0 \\
(0)\end{array}$ & $\begin{array}{l}3 \\
(100)\end{array}$ & $\begin{array}{l}0 \\
(0)\end{array}$ & $\begin{array}{l}2 \\
(100)\end{array}$ & $\begin{array}{l}0 \\
(0)\end{array}$ & $\begin{array}{l}0 \\
(0)\end{array}$ & $\begin{array}{l}2 \\
(100)\end{array}$ & $\begin{array}{l}1 \\
(50)\end{array}$ & $\begin{array}{l}1 \\
(50)\end{array}$ & $\begin{array}{l}0 \\
(0)\end{array}$ & $\begin{array}{l}1 \\
(100)\end{array}$ \\
\hline Levofloxacin & $\begin{array}{l}8 \\
(31)\end{array}$ & $\begin{array}{l}18 \\
(69)\end{array}$ & $\begin{array}{l}0 \\
(0)\end{array}$ & $\begin{array}{l}1 \\
(100)\end{array}$ & $\begin{array}{l}17 \\
(37)\end{array}$ & $\begin{array}{l}29 \\
(63)\end{array}$ & $\begin{array}{l}1 \\
(100)\end{array}$ & $\begin{array}{l}0 \\
(0)\end{array}$ & $\begin{array}{l}3 \\
(100)\end{array}$ & $\begin{array}{l}0 \\
(0)\end{array}$ & $\begin{array}{l}2 \\
(100)\end{array}$ & $\begin{array}{l}0 \\
(0)\end{array}$ & $\begin{array}{l}0 \\
(0)\end{array}$ & $\begin{array}{l}2 \\
(100)\end{array}$ & $\begin{array}{l}1 \\
(50)\end{array}$ & $\begin{array}{l}1 \\
(50)\end{array}$ & $\begin{array}{l}0 \\
(0)\end{array}$ & $\begin{array}{l}1 \\
(100)\end{array}$ \\
\hline $\begin{array}{l}\text { Trimethoprim/ } \\
\text { Sulfamethoxazole }\end{array}$ & $\begin{array}{l}3 \\
(11.5)\end{array}$ & $\begin{array}{l}23 \\
(88.5)\end{array}$ & $\begin{array}{l}0 \\
(0)\end{array}$ & $\begin{array}{l}1 \\
(100)\end{array}$ & $\begin{array}{l}11 \\
(24)\end{array}$ & $\begin{array}{l}35 \\
(76)\end{array}$ & $\begin{array}{l}1 \\
(100)\end{array}$ & $\begin{array}{l}0 \\
(0)\end{array}$ & $\begin{array}{l}3 \\
(100)\end{array}$ & $\begin{array}{l}0 \\
(0)\end{array}$ & $\begin{array}{l}1 \\
(50)\end{array}$ & $\begin{array}{l}1 \\
(50)\end{array}$ & $\begin{array}{l}0 \\
(0)\end{array}$ & $\begin{array}{l}2 \\
(100)\end{array}$ & $\begin{array}{l}0 \\
(0)\end{array}$ & $\begin{array}{l}2 \\
(100)\end{array}$ & $\begin{array}{l}0 \\
(0)\end{array}$ & $\begin{array}{l}1 \\
(100)\end{array}$ \\
\hline Total & 26 & & 1 & & 46 & & 1 & & 3 & & 2 & & 2 & & 2 & & 1 & \\
\hline
\end{tabular}

M.O: microorganism; AB: antibiotic disc name; n: number; $\mathrm{S}$ : sensitive; R: resistance

Table 3. Antibiotic susceptibility pattern of Non fermentative Gram negative bacilli.

\begin{tabular}{|c|c|c|c|c|c|c|c|c|c|c|c|c|c|c|}
\hline \multirow[b]{2}{*}{ AB } & \multicolumn{2}{|c|}{$\begin{array}{l}\text { Acinetobacter } \\
\text { baumannii }\end{array}$} & \multicolumn{2}{|c|}{$\begin{array}{l}\text { Acinetobacter } \\
\text { hemolyticus }\end{array}$} & \multicolumn{2}{|c|}{$\begin{array}{l}\text { Stenotrophoms } \\
\text { maltophilia }\end{array}$} & \multicolumn{2}{|c|}{$\begin{array}{l}\text { Burkholderia } \\
\text { cepacia }\end{array}$} & \multicolumn{2}{|c|}{$\begin{array}{l}\text { Pseudomonas } \\
\text { aeruginosa }\end{array}$} & \multicolumn{2}{|c|}{$\begin{array}{l}\text { Pseudomonas } \\
\text { fluorescence }\end{array}$} & \multicolumn{2}{|c|}{$\begin{array}{l}\text { Pseudomonas } \\
\text { oryzihabitans }\end{array}$} \\
\hline & $\begin{array}{l}\text { S } \\
\text { n } \\
(\%) \\
\end{array}$ & $\begin{array}{l}\text { R } \\
\mathbf{n} \\
(\%) \\
\end{array}$ & $\begin{array}{l}\text { S } \\
\text { n } \\
(\%) \\
\end{array}$ & $\begin{array}{l}\text { R } \\
\mathbf{n} \\
(\%) \\
\end{array}$ & $\begin{array}{l}\text { S } \\
\text { n } \\
(\%) \\
\end{array}$ & $\begin{array}{l}\text { R } \\
\mathbf{n} \\
(\%) \\
\end{array}$ & $\begin{array}{l}\text { S } \\
\text { n } \\
(\%) \\
\end{array}$ & $\begin{array}{l}\text { R } \\
\mathbf{n} \\
(\%) \\
\end{array}$ & $\begin{array}{l}\text { S } \\
\text { n } \\
(\%) \\
\end{array}$ & $\begin{array}{l}\mathbf{R} \\
\mathbf{n} \\
\%)( \\
\end{array}$ & $\begin{array}{l}\text { S } \\
\text { n } \\
(\%) \\
\end{array}$ & $\begin{array}{l}\mathbf{R} \\
\mathbf{n} \\
(\%) \\
\end{array}$ & $\begin{array}{l}\text { S } \\
\text { n } \\
(\%) \\
\end{array}$ & $\begin{array}{l}\text { R } \\
\text { n } \\
(\%) \\
\end{array}$ \\
\hline Ampicillin & $\begin{array}{l}0 \\
(0)\end{array}$ & $\begin{array}{l}22 \\
(100)\end{array}$ & $\begin{array}{l}0 \\
(0)\end{array}$ & $\begin{array}{l}1 \\
(100)\end{array}$ & $\begin{array}{l}0 \\
(0)\end{array}$ & $\begin{array}{l}4 \\
(100)\end{array}$ & $\begin{array}{l}0 \\
(0)\end{array}$ & $\begin{array}{l}1 \\
(100)\end{array}$ & $\begin{array}{l}0 \\
(0)\end{array}$ & $\begin{array}{l}14 \\
(100)\end{array}$ & $\begin{array}{l}0 \\
(0)\end{array}$ & $\begin{array}{l}1 \\
(100)\end{array}$ & $\begin{array}{l}0 \\
(0)\end{array}$ & $\begin{array}{l}1 \\
(100)\end{array}$ \\
\hline $\begin{array}{l}\text { Amoxicillin/ } \\
\text { Clavulanic acid }\end{array}$ & $\begin{array}{l}0 \\
(0)\end{array}$ & $\begin{array}{l}22 \\
(100)\end{array}$ & $\begin{array}{l}0 \\
(0)\end{array}$ & $\begin{array}{l}1 \\
(100)\end{array}$ & $\begin{array}{l}0 \\
(0)\end{array}$ & $\begin{array}{l}4 \\
(100)\end{array}$ & $\begin{array}{l}0 \\
(0)\end{array}$ & $\begin{array}{l}1 \\
(100)\end{array}$ & $\begin{array}{l}0 \\
(0)\end{array}$ & $\begin{array}{l}14 \\
(100)\end{array}$ & $\begin{array}{l}0 \\
(0)\end{array}$ & $\begin{array}{l}1 \\
(100)\end{array}$ & $\begin{array}{l}1 \\
(100)\end{array}$ & $\begin{array}{l}0 \\
(0)\end{array}$ \\
\hline $\begin{array}{l}\text { Ampicillin/ } \\
\text { Sulbactam }\end{array}$ & $\begin{array}{l}1 \\
(4.5)\end{array}$ & $\begin{array}{l}21 \\
(95.5)\end{array}$ & $\begin{array}{l}0 \\
(0)\end{array}$ & $\begin{array}{l}1 \\
(100)\end{array}$ & $\begin{array}{l}0 \\
(0)\end{array}$ & $\begin{array}{l}4 \\
(100)\end{array}$ & $\begin{array}{l}0 \\
(0)\end{array}$ & $\begin{array}{l}1 \\
(100)\end{array}$ & $\begin{array}{l}0 \\
(0)\end{array}$ & $\begin{array}{l}14 \\
(100)\end{array}$ & $\begin{array}{l}0 \\
(0)\end{array}$ & $\begin{array}{l}1 \\
(100)\end{array}$ & $\begin{array}{l}0 \\
(0)\end{array}$ & $\begin{array}{l}1 \\
(100)\end{array}$ \\
\hline $\begin{array}{l}\text { Piperacillin/ } \\
\text { Tazobactam }\end{array}$ & $\begin{array}{l}1 \\
(4.5)\end{array}$ & $\begin{array}{l}21 \\
(95.5)\end{array}$ & $\begin{array}{l}0 \\
(0)\end{array}$ & $\begin{array}{l}1 \\
(100)\end{array}$ & $\begin{array}{l}1 \\
(25)\end{array}$ & $\begin{array}{l}3 \\
(75)\end{array}$ & $\begin{array}{l}0 \\
(0)\end{array}$ & $\begin{array}{l}1 \\
(100)\end{array}$ & $\begin{array}{l}6 \\
(43)\end{array}$ & $\begin{array}{l}8 \\
(57)\end{array}$ & $\begin{array}{l}0 \\
(0)\end{array}$ & $\begin{array}{l}1 \\
(100)\end{array}$ & $\begin{array}{l}1 \\
(100)\end{array}$ & $\begin{array}{l}0 \\
(0)\end{array}$ \\
\hline Piperacillin & $\begin{array}{l}0 \\
(0)\end{array}$ & $\begin{array}{l}22 \\
(100)\end{array}$ & $\begin{array}{l}0 \\
(0)\end{array}$ & $\begin{array}{l}1 \\
(100)\end{array}$ & $\begin{array}{l}0 \\
(0)\end{array}$ & $\begin{array}{l}4 \\
(100)\end{array}$ & $\begin{array}{l}0 \\
(0)\end{array}$ & $\begin{array}{l}1 \\
(100)\end{array}$ & $\begin{array}{l}0 \\
(0)\end{array}$ & $\begin{array}{l}14 \\
(100)\end{array}$ & $\begin{array}{l}0 \\
(0)\end{array}$ & $\begin{array}{l}1 \\
(100)\end{array}$ & $\begin{array}{l}0 \\
(0)\end{array}$ & $\begin{array}{l}1 \\
(100)\end{array}$ \\
\hline Azteronam & 0 & 22 & 0 & 1 & 0 & 4 & 0 & 1 & 2 & 12 & 0 & 1 & 1 & 0 \\
\hline
\end{tabular}




\begin{tabular}{|c|c|c|c|c|c|c|c|c|c|c|c|c|c|c|}
\hline \multirow[b]{2}{*}{ AB } & \multicolumn{2}{|c|}{$\begin{array}{l}\text { Acinetobacter } \\
\text { baumannii }\end{array}$} & \multicolumn{2}{|c|}{$\begin{array}{l}\text { Acinetobacter } \\
\text { hemolyticus }\end{array}$} & \multicolumn{2}{|c|}{$\begin{array}{l}\text { Stenotrophoms } \\
\text { maltophilia }\end{array}$} & \multicolumn{2}{|c|}{$\begin{array}{l}\text { Burkholderia } \\
\text { cepacia }\end{array}$} & \multicolumn{2}{|c|}{$\begin{array}{l}\text { Pseudomonas } \\
\text { aeruginosa }\end{array}$} & \multicolumn{2}{|c|}{$\begin{array}{l}\text { Pseudomonas } \\
\text { fluorescence }\end{array}$} & \multicolumn{2}{|c|}{$\begin{array}{l}\text { Pseudomonas } \\
\text { oryzihabitans }\end{array}$} \\
\hline & $\begin{array}{l}\text { S } \\
\text { n } \\
(\%)\end{array}$ & $\begin{array}{l}\text { R } \\
\text { n } \\
(\%)\end{array}$ & $\begin{array}{l}\text { S } \\
\text { n } \\
(\%)\end{array}$ & $\begin{array}{l}\text { R } \\
\text { n } \\
(\%)\end{array}$ & $\begin{array}{l}\text { S } \\
\text { n } \\
(\%)\end{array}$ & $\begin{array}{l}\text { R } \\
\text { n } \\
(\%)\end{array}$ & $\begin{array}{l}\text { S } \\
\text { n } \\
(\%)\end{array}$ & $\begin{array}{l}\text { R } \\
\text { n } \\
(\%)\end{array}$ & $\begin{array}{l}\text { S } \\
\text { n } \\
(\%)\end{array}$ & $\begin{array}{l}\mathbf{R} \\
\mathbf{n} \\
\mathbf{\%})(\end{array}$ & $\begin{array}{l}\text { S } \\
\text { n } \\
(\%)\end{array}$ & $\begin{array}{l}\text { R } \\
\mathrm{n} \\
(\%)\end{array}$ & $\begin{array}{l}\text { S } \\
\text { n } \\
(\%)\end{array}$ & $\begin{array}{l}\text { R } \\
\mathrm{n} \\
(\%)\end{array}$ \\
\hline & (0) & $(100)$ & (0) & $(100)$ & (0) & (100) & (0) & $(100)$ & (14) & (86) & (0) & (100) & $(100)$ & $(0)$ \\
\hline Imipenem & $\begin{array}{l}3 \\
(14)\end{array}$ & $\begin{array}{l}19 \\
(86)\end{array}$ & $\begin{array}{l}0 \\
(0)\end{array}$ & $\begin{array}{l}1 \\
(100)\end{array}$ & $\begin{array}{l}0 \\
(0)\end{array}$ & $\begin{array}{l}4 \\
(100)\end{array}$ & $\begin{array}{l}0 \\
(0)\end{array}$ & $\begin{array}{l}1 \\
(100)\end{array}$ & $\begin{array}{l}7 \\
(50)\end{array}$ & $\begin{array}{l}7 \\
(50)\end{array}$ & $\begin{array}{l}1 \\
(100)\end{array}$ & $\begin{array}{l}0 \\
(0)\end{array}$ & $\begin{array}{l}1 \\
(100)\end{array}$ & $\begin{array}{l}0 \\
(0)\end{array}$ \\
\hline Meropenem & $\begin{array}{l}3 \\
(14)\end{array}$ & $\begin{array}{l}19 \\
(86)\end{array}$ & $\begin{array}{l}0 \\
(0)\end{array}$ & $\begin{array}{l}1 \\
(100)\end{array}$ & $\begin{array}{l}0 \\
(0)\end{array}$ & $\begin{array}{l}4 \\
(100)\end{array}$ & $\begin{array}{l}0 \\
(0)\end{array}$ & $\begin{array}{l}1 \\
(100)\end{array}$ & $\begin{array}{l}6 \\
(43)\end{array}$ & $\begin{array}{l}8 \\
(57)\end{array}$ & $\begin{array}{l}1 \\
(100)\end{array}$ & $\begin{array}{l}0 \\
(0)\end{array}$ & $\begin{array}{l}1 \\
(100)\end{array}$ & $\begin{array}{l}0 \\
(0)\end{array}$ \\
\hline Cefoxitin & $\begin{array}{l}0 \\
(0)\end{array}$ & $\begin{array}{l}22 \\
(100)\end{array}$ & $\begin{array}{l}0 \\
(0)\end{array}$ & $\begin{array}{l}1 \\
(100)\end{array}$ & $\begin{array}{l}0 \\
(0)\end{array}$ & $\begin{array}{l}4 \\
(100)\end{array}$ & $\begin{array}{l}0 \\
(0)\end{array}$ & $\begin{array}{l}1 \\
(100)\end{array}$ & $\begin{array}{l}1 \\
\text { (7) }\end{array}$ & $\begin{array}{l}13 \\
(93)\end{array}$ & $\begin{array}{l}0 \\
(0)\end{array}$ & $\begin{array}{l}1 \\
(100)\end{array}$ & $\begin{array}{l}0 \\
(0)\end{array}$ & $\begin{array}{l}1 \\
(100)\end{array}$ \\
\hline Ceftazidim & $\begin{array}{l}1 \\
(4.5)\end{array}$ & $\begin{array}{l}21 \\
(95.5)\end{array}$ & $\begin{array}{l}0 \\
(0)\end{array}$ & $\begin{array}{l}1 \\
(100)\end{array}$ & $\begin{array}{l}0 \\
(0)\end{array}$ & $\begin{array}{l}4 \\
(100)\end{array}$ & $\begin{array}{l}0 \\
(0)\end{array}$ & $\begin{array}{l}1 \\
(100)\end{array}$ & $\begin{array}{l}1 \\
(7)\end{array}$ & $\begin{array}{l}13 \\
(93)\end{array}$ & $\begin{array}{l}1 \\
(100)\end{array}$ & $\begin{array}{l}0 \\
(0)\end{array}$ & $\begin{array}{l}1 \\
(100)\end{array}$ & $\begin{array}{l}0 \\
(0)\end{array}$ \\
\hline Cefotaxime & $\begin{array}{l}0 \\
(0)\end{array}$ & $\begin{array}{l}22 \\
(100)\end{array}$ & $\begin{array}{l}0 \\
(0)\end{array}$ & $\begin{array}{l}1 \\
(100)\end{array}$ & $\begin{array}{l}0 \\
(0)\end{array}$ & $\begin{array}{l}4 \\
(100)\end{array}$ & $\begin{array}{l}0 \\
(0)\end{array}$ & $\begin{array}{l}1 \\
(100)\end{array}$ & $\begin{array}{l}1 \\
(7)\end{array}$ & $\begin{array}{l}13 \\
(93)\end{array}$ & $\begin{array}{l}0 \\
(0)\end{array}$ & $\begin{array}{l}1 \\
(100)\end{array}$ & $\begin{array}{l}1 \\
(100)\end{array}$ & $\begin{array}{l}0 \\
(0)\end{array}$ \\
\hline Ceftriaxone & $\begin{array}{l}0 \\
(0)\end{array}$ & $\begin{array}{l}22 \\
(100)\end{array}$ & $\begin{array}{l}0 \\
(0)\end{array}$ & $\begin{array}{l}1 \\
(100)\end{array}$ & $\begin{array}{l}0 \\
(0)\end{array}$ & $\begin{array}{l}4 \\
(100)\end{array}$ & $\begin{array}{l}0 \\
(0)\end{array}$ & $\begin{array}{l}1 \\
(100)\end{array}$ & $\begin{array}{l}0 \\
(0)\end{array}$ & $\begin{array}{l}14 \\
(100)\end{array}$ & $\begin{array}{l}1 \\
(100)\end{array}$ & $\begin{array}{l}0 \\
(0)\end{array}$ & $\begin{array}{l}0 \\
(0)\end{array}$ & $\begin{array}{l}1 \\
(100)\end{array}$ \\
\hline Amikacin & $\begin{array}{l}3 \\
\text { (14) }\end{array}$ & $\begin{array}{l}19 \\
(86)\end{array}$ & $\begin{array}{l}0 \\
(0)\end{array}$ & $\begin{array}{l}1 \\
(100)\end{array}$ & $\begin{array}{l}1 \\
(25)\end{array}$ & $\begin{array}{l}3 \\
(75)\end{array}$ & $\begin{array}{l}0 \\
(0)\end{array}$ & $\begin{array}{l}1 \\
(100)\end{array}$ & $\begin{array}{l}8 \\
(57)\end{array}$ & $\begin{array}{l}6 \\
(43)\end{array}$ & $\begin{array}{l}1 \\
(100)\end{array}$ & $\begin{array}{l}0 \\
(0)\end{array}$ & $\begin{array}{l}1 \\
(100)\end{array}$ & $\begin{array}{l}0 \\
(0)\end{array}$ \\
\hline Gentamicin & $\begin{array}{l}7 \\
\text { (32) }\end{array}$ & $\begin{array}{l}15 \\
(68)\end{array}$ & $\begin{array}{l}0 \\
(0)\end{array}$ & $\begin{array}{l}1 \\
(100)\end{array}$ & $\begin{array}{l}2 \\
(50)\end{array}$ & $\begin{array}{l}2 \\
(50)\end{array}$ & $\begin{array}{l}0 \\
(0)\end{array}$ & $\begin{array}{l}1 \\
(100)\end{array}$ & $\begin{array}{l}6 \\
(43)\end{array}$ & $\begin{array}{l}8 \\
(57)\end{array}$ & $\begin{array}{l}1 \\
(100)\end{array}$ & $\begin{array}{l}0 \\
(0)\end{array}$ & $\begin{array}{l}0 \\
(0)\end{array}$ & $\begin{array}{l}1 \\
(100)\end{array}$ \\
\hline Tobramycin & $\begin{array}{l}5 \\
(23)\end{array}$ & $\begin{array}{l}17 \\
(77)\end{array}$ & $\begin{array}{l}0 \\
(0)\end{array}$ & $\begin{array}{l}1 \\
(100)\end{array}$ & $\begin{array}{l}0 \\
(0)\end{array}$ & $\begin{array}{l}4 \\
(100)\end{array}$ & $\begin{array}{l}0 \\
(0)\end{array}$ & $\begin{array}{l}1 \\
(100)\end{array}$ & $\begin{array}{l}3 \\
\text { (21) }\end{array}$ & $\begin{array}{l}11 \\
\text { (79) }\end{array}$ & $\begin{array}{l}0 \\
(0)\end{array}$ & $\begin{array}{l}1 \\
(100)\end{array}$ & $\begin{array}{l}1 \\
(100)\end{array}$ & $\begin{array}{l}0 \\
(0)\end{array}$ \\
\hline Tetracycline & $\begin{array}{l}2 \\
\text { (9) }\end{array}$ & $\begin{array}{l}20 \\
(91)\end{array}$ & $\begin{array}{l}0 \\
(0)\end{array}$ & $\begin{array}{l}1 \\
(100)\end{array}$ & $\begin{array}{l}0 \\
(0)\end{array}$ & $\begin{array}{l}4 \\
(100)\end{array}$ & $\begin{array}{l}0 \\
(0)\end{array}$ & $\begin{array}{l}1 \\
(100)\end{array}$ & $\begin{array}{l}0 \\
(0)\end{array}$ & $\begin{array}{l}14 \\
(100)\end{array}$ & $\begin{array}{l}1 \\
(100)\end{array}$ & $\begin{array}{l}0 \\
(0)\end{array}$ & $\begin{array}{l}0 \\
(0)\end{array}$ & $\begin{array}{l}1 \\
(100)\end{array}$ \\
\hline Tygacil & $\begin{array}{l}5 \\
(23)\end{array}$ & $\begin{array}{l}17 \\
(77)\end{array}$ & $\begin{array}{l}0 \\
(0)\end{array}$ & $\begin{array}{l}1 \\
(100)\end{array}$ & $\begin{array}{l}0 \\
(0)\end{array}$ & $\begin{array}{l}4 \\
(100)\end{array}$ & $\begin{array}{l}0 \\
(0)\end{array}$ & $\begin{array}{l}1 \\
(100)\end{array}$ & $\begin{array}{l}4 \\
\text { (29) }\end{array}$ & $\begin{array}{l}10 \\
(71)\end{array}$ & $\begin{array}{l}0 \\
(0)\end{array}$ & $\begin{array}{l}1 \\
(100)\end{array}$ & $\begin{array}{l}0 \\
(0)\end{array}$ & $\begin{array}{l}1 \\
(100)\end{array}$ \\
\hline Ciprofloxacin & $\begin{array}{l}3 \\
\text { (14) }\end{array}$ & $\begin{array}{l}19 \\
(86)\end{array}$ & $\begin{array}{l}0 \\
(0)\end{array}$ & $\begin{array}{l}1 \\
(100)\end{array}$ & $\begin{array}{l}1 \\
(25)\end{array}$ & $\begin{array}{l}3 \\
(75)\end{array}$ & $\begin{array}{l}0 \\
(0)\end{array}$ & $\begin{array}{l}1 \\
(100)\end{array}$ & $\begin{array}{l}5 \\
(36)\end{array}$ & $\begin{array}{l}9 \\
(64)\end{array}$ & $\begin{array}{l}1 \\
(100)\end{array}$ & $\begin{array}{l}0 \\
(0)\end{array}$ & $\begin{array}{l}1 \\
(100)\end{array}$ & $\begin{array}{l}0 \\
(0)\end{array}$ \\
\hline Levofloxacin & $\begin{array}{l}3 \\
\text { (14) }\end{array}$ & $\begin{array}{l}19 \\
(86)\end{array}$ & $\begin{array}{l}0 \\
(0)\end{array}$ & $\begin{array}{l}1 \\
(100)\end{array}$ & $\begin{array}{l}2 \\
(50)\end{array}$ & $\begin{array}{l}2 \\
(50)\end{array}$ & $\begin{array}{l}0 \\
(0)\end{array}$ & $\begin{array}{l}1 \\
(100)\end{array}$ & $\begin{array}{l}6 \\
(43)\end{array}$ & $\begin{array}{l}8 \\
(57)\end{array}$ & $\begin{array}{l}1 \\
(100)\end{array}$ & $\begin{array}{l}0 \\
(0)\end{array}$ & $\begin{array}{l}1 \\
(100)\end{array}$ & $\begin{array}{l}0 \\
(0)\end{array}$ \\
\hline $\begin{array}{l}\text { Trimethoprim/ } \\
\text { Sulfamethoxazole }\end{array}$ & $\begin{array}{l}1 \\
(4.5)\end{array}$ & $\begin{array}{l}21 \\
(95.5)\end{array}$ & $\begin{array}{l}0 \\
(0)\end{array}$ & $\begin{array}{l}1 \\
(100)\end{array}$ & $\begin{array}{l}0 \\
(0)\end{array}$ & $\begin{array}{l}4 \\
(100)\end{array}$ & $\begin{array}{l}0 \\
(0)\end{array}$ & $\begin{array}{l}1 \\
(100)\end{array}$ & $\begin{array}{l}2 \\
(14)\end{array}$ & $\begin{array}{l}12 \\
(86)\end{array}$ & $\begin{array}{l}0 \\
(0)\end{array}$ & $\begin{array}{l}1 \\
(100)\end{array}$ & $\begin{array}{l}0 \\
(0)\end{array}$ & $\begin{array}{l}1 \\
(100)\end{array}$ \\
\hline Total & 22 & & 1 & & 4 & & 1 & & 14 & & 1 & & 1 & \\
\hline
\end{tabular}

M.O: microorganism; AB: antibiotic disc name; n: number; S: sensitive; R: resistance

In the current study, GNB were found associated with LRTI in cancer patients. Among GNB isolated, we observed an increase in Enterobacteriaceae especially Klebsiella species. K. pneumoniae $(35.4 \%)$ was the most frequently isolated bacterial strains followed by E. coli (20\%).

Other studies have also reported that, Klebsiella species were among the most frequent Gram negative isolates from respiratory tract infection $[26,27,28]$.

$P$. aeruginosa has also been reported to cause a wide variety of infections in cancer patients as it is a common hospital and opportunistic pathogen [29, 30].

In the present study a number of less-frequent Gram negative bacteria (17\%) were isolated and identified (Acinetobacter haemolyticus, Burkholderia cepacia, Chromobacterium violacum, Citrobacter freundil, Chryseobacterium meningosepticum, Enterobacter aerogenes, Enterobacter cloacae, Escherichia vulneris, Klebsiella ozanae, Providencia stuarti, Pseudomonas fluorescence, Pseudomonas oryzihabitant, Serratia marcescens and Stenotrophomonas maltophilia).

Gram negative pathogens of increasing importance in cancer patients include Stenotrophomonas maltophilia and emerging pathogen Burkholderia cepacia [23]. In this study, $3 \%$ of Gram negative bacilli were found to be multidrug resistant Stenotrophomonas maltophilia. Stenotrophomonas maltophilia is an organism that is frequently isolated from the environment, particularly from water supplies. The incidence of Stenotrophomonas maltophilia hospital acquired infections are increasing, particularly in the immunocompromised patient population receiving broadspectrum antibiotics [23, 31].

The isolation of Burkholderia cepacia and other less frequent Gram negative bacilli had been reported as nosocomial infections among immunocompromised patients $[32,33]$

The presence or absence of Legionella DNA in specimens might be clinically significant because of that legionella is not part from the human flora [34]. Sputum culture and PCR testing of lower respiratory tract specimens are the most important tools for diagnosis and detection of Legionella infection [35]. In the present study sputum specimens, were cultured on BCYE agar for detection of Legionella pneumophila and subjected to DNA extraction with subsequent PCR amplification for detection of specific DNA sequences of Legionella pneumophila. Our result revealed that there was no legionella detected by using both methods. We suggest that could be attributed to two reasons first, the studied patients were received antibiotics active against Legionella species as empiric therapy without undergoing laboratory testing for Legionella species. Second, good 
decontaminated procedure of the water system of the hospital (the place which specimens were collected) because other studies suggested that outbreaks or sporadic cases of legionellosis may arise from contaminated water systems of the hospitals [36, 37]

In the present study, amikacin followed by imipenem then meropenem were the most effective drugs against Gram negative bacterial strains. Amikacin appeared to have wider range of activity than tobramycin, gentamicin and other tested antimicrobial agents and this is consistent with other studies $[38,39]$. This may be attributed to that amikacin has lower selective pressure due to their restricted use. Other study explained the efficiency of amikacin by the fact that these are very powerful drugs used only in hospital settings and not as first-line therapy (39). With respect to amikacin resistance in our study, it appears that amikacin may be used as the primary antibiotics for the treatment of GNB in Egypt.

Quinolone prophylaxis has been widely used in cancer patients to decrease the risk of Gram negative infections [40]. However, it has been associated with an increased risk of selection of resistant strains [41]. The emergence of lower respiratory tract infections quinolone-resistant Gram negative bacterial was observed in our study. E. coli exhibited high resistance to ciprofloxacin (77\%) and to levofloxacin (69\%). A similar trend was seen with $P$. aeruginosa which exhibited resistance to ciprofloxacin (64\%) and to levofloxacin (57\%). $K$. pneumoniae exhibited resistance to levofloxacin and ciprofloxacin (63\% each). Also, A. baumannii exhibited resistance to ciprofloxacin and levofloxacin (86\% each).

In general $K$. pneumoniae are resistant to abroad range of antimicrobial agents, and practically always resistance to ampicillin and amoxicillin naturally [42]. In this study, $K$. pneumoniae strains were $100 \%$ resistance to ampicillin and piperacillin. The lowest percentage of susceptibility was manifested against ampicillin/sulbactam (4\%) and ceftriaxone $(6.5 \%)$ whereas more susceptibility was observed with amikacin $(70 \%)$ followed by imipenem $(61 \%)$ then meropenem (59\%). E. coli isolates exhibit high resistance pattern. Another study reported that E. coli isolates from cancer patients in Egypt exhibited a low susceptibility pattern [43].

Resistance rates of $A$. baumannii were reported as $86 \%$ against ciprofloxacin, imipenem, meropenem and amikacin and $95.5 \%$ against piperacillin/tazobactam.

We demonstrated that $P$. aeruginosa were resistant to multiple antibiotics, that way rendering current antibiotic therapy ineffective. This could be attributed to the fact that $P$. aeruginosa has intrinsic antibiotics resistance due to low outer membrane permeability, as well as an extensive efflux pump system [44].

In current study, Acinetobacter and Pseudomonas species exhibited the highest resistance levels to imipenem. E. coli and Klebsiella exhibited lower resistance to imipenem. Previous studies in Egypt reported that resistance to imipenem was totally absent or very low [43, 45]. This discrepancy can be attributed to continue development of resistant strains in Egypt and improper use of empirical antibiotics.

The most significant public health threat is the emergence of resistance to multiple antimicrobial agents in pathogenic bacteria [18].

The phenomenon of multi-drug resistant pathogens had emerged in Egypt and worldwide due to excessive antibiotic misuse [43. 46, 47]. Several studies reported an increase in multi-drug resistant GNB in immunocompetent and immunocompromised patients, including patients with malignancies [43, 46, 47].

In our study the most notable finding was the highly increase in multidrug-resistant Gram negative bacilli (96\%).

\section{Conclusion}

Current study demonstrated that Legionella pneumophila are not a common cause of lower respiratory tract infection among cancer patients in Egypt. Regarding Gram negative bacilli infection, amikacin would be a discreet choice in highrisk cases. Gram negative bacilli resistant to most classes of antibiotics in this study are due to inappropriate use of these drugs. In order to limit the emergence of multi-drug resistant Gram negative bacteria in Egypt, antimicrobial confined policies should be applied.

\section{References}

[1] Oh YW, Effmann EL, Godwin JD (2000) Pulmonary infections in immunocompromised hosts: the importance of correlating the conventional radiologic appearance with the clinical setting. Radiology 217: 647-56.

[2] Renaud C, Campbell AP (2011) Changing epidemiology of respiratory viral infections in hematopoietic cell transplant recipients and solid organ transplant recipients. Curr Opin Infect Dis 24:333-43.

[3] Woodhead M, Blasi F, Ewig S, Garau J, Huchon G, Leven M (2011) Guidelines for the management of adult lower respiratory tract infections - Full version. Clin Microbiol Infect 17 Suppl 6: E1-59.

[4] Kim YJ, Boeckh M, Englund JA (2007) Community respiratory virus infections in immunocompromised patients: Hematopoietic stem cell and solid organ transplant recipients, and individuals with human immunodeficiency virus infection. Semin Respir Crit Care Med 28(2):222-242.

[5] Junghanss C, Marr KA, Carter RA, Sandmaier BM, Maris MB Maloney DG, Chauncey T, McSweeney PA, Storb R (2002) Incidence and Outcome of Bacterial and Fungal Infections following Nonmyeloablative Compared with myeloablative allogeneic hematopoietic stem cell transplantation: a matched control study. Biology of Blood and Marrow Transplantation 8:512-520.

[6] Clark JG, Crawford SW (1978) Diagnostic Approaches to pulmonary complications of marrow transplantation. Chest 1028-34.

[7] Harrington RD, Woolfrey AE, Bowden R, McDowell MG, Hackman RC (1996) Legionellosis in a bone marrow transplant center. Bone Marrow Transplant 18(2): 361-8. 
[8] Stout JE, Yu VL (2003) Hospital-acquired Legionnaires'disease: new developments. Curr Opin Infect Dis 16: 337-341.

[9] Reingold AL, Thomason BM, Brake BJ, Thacker L, Wilkinson HW, Kuritsky JN (1984) Legionella pneumonia in the United States: the distribution of serogroups and species causing human illness. J Infect Dis 149:819.

[10] Munder RU (2000) Other Legionella Species. In Mandell GL, Bennett JE, Dolin R, editors. Principles and practice of infectious diseases, 5th edition. vol. 2. Churchill Livingstone, Philadelphia, 2435-2441.

[11] Yu VL (2000) Legionella pneumophila. In Mandell GL, Bennett JE, Dolin R, editors. Principles and practice of infectious diseases, 5th edition. vol. 2. Churchill Livingstone, Philadelphia, 2424-2435.

[12] Pop-Vicas AE, D'Agata EMC (2005) The rising influx of multidrug-resistant Gram-negative bacilli into a tertiary care Hospital. Clin Infect Dis 40: 1792-1798.

[13] Schwaber MJ, Navon-Venezia S, Kaye KS, Ben-Ami R, Schwartz D, Carmeli Y (2006) Clinical and economic impact of bacteremia with extended spectrum--lactamase-producing enterobacteriaceae. Antimicrobial Agents and Chemotherapy 50(4): 1257-1262.

[14] Winn WJ, Allen S, Janda W, Koneman EW, Procop G, Schreckenberger P, Wood G (2006) Color Atlas and Textbook of Diagnostic Microbiology, sixth edition. Philadelphia, Lippincott Co. J Clin Microbiol 32: 209-210.

[15] Ingram JG, Plouffe JF (1994) Danger of sputum purulence screens in culture of Legionella species.

[16] Morrill WE, Barbaree JM, Fields BS, Sanden GN, Martin WT (1990) Increased recovery of Legionella micdadei and Legionella bozemanii on buffered charcoal yeast extract agar supplemented with albumin. J Clin Microbiol 28:616-8.

[17] 1Clinical and Laboratory Standards Institute (CLSI) (2011) Performance standards for Antimicrobial Susceptibility Testing; Twenty First Informational Supplements. CLSI Document M100-S21, Wayne PA.

[18] 1Magiorakos AP, Srinivasan A, Carey RB, Carmeli Y, Falagas ME, Giske CG, Harbarth S, Hindler JF, Kahlmeter G, OlssonLiljequist B, Paterson DL, Rice LB, Stelling J, Struelens MJ, Vatopoulos A, Weber JT, Monnet DL (2012) Multidrug-resistant extensively drug-resistant and pandrug-resistant bacteria: an international expert proposal for interim standard definitions for acquired resistance. Clin Microbiol Infect 18: 268-281.

[19] Rantakokko-Jalava K, Jalava J (2001) Development of Conventional and Real-Time PCR Assays for Detection of Legionella DNA in Respiratory Specimens. J. Clin. Microbiol 39(8): 2904-2910.

[20] Nosari A, Barberis M, Landonio G, Magnani P, Majno M, Oreste P, Sozzi P (1991) Infections in haematologic neoplasms: autopsy findings. Haematologica 76 (2):135-140.

[21] Homsi J, Walsh D, Panta R, Lagman R, Nelson KA, Longworth DL (2000) Infectious complications of advanced cancer. Support Care Cancer 8(6):487-492.

[22] Glauser MP, Zinner SH (1982) Mechanisms of acquisition and development of bacterial infections in cancer patients. In Klastersky J editors. Infections in cancer patients. New York: Raven Press. 13-30.
[23] Stosor V, Zembower TR (2014) Epidemiology of Infections in Cancer Patients. Cancer Treatment and Research 161: 43-89.

[24] Montassier E, Batard E, Gastinne T, Potel G, de La Cochetière MF (2013) Recent changes in bacteremia in patients with cancer: a systematic review of epidemiology and antibiotic resistance. Eur J Clin Microbiol Infect Dis 32(7):841-850.

[25] Gudiol C, Bodro M, Simonetti A, Tubau F, González-Barca E, Cisnal M, Domingo-Domenech E, Jiménez L, Carratalà J (2013) Changing aetiology, clinical features, antimicrobial resistance, and outcomes of bloodstream infection in neutropenic cancer patients. Clin Microbiol Infect 19 (5):474479.

[26] Shyamala R, Rao J (2014) Klebsiella pneumonia: A common pathogen causing bacterial pneumonia in a teaching hospital. J. Microbiol. Biotech. Res 4 (1):7-10.

[27] Gonlugur U, Bakici MZ, Akkurt I, Efeoglu T (2004) Antibiotic susceptibility patterns among respiratory isolates of Gram-negative bacilli in a Turkish university hospital. BMC Microbiol 4: 32.

[28] Vishwanath S, Chawla K, Gopinathan A (2013) Multidrug resistant Gram-negative bacilli in lower respiratory tract infections. Iran. J. Microbiol 5: 323-327.

[29] Oudhuis GJ, Verbon A, Hoogkamp-Korstanje JA, Stobberingh EE (2008) Susceptibility Surveillance Study Group. Susceptibility Surveillance Study Group. Antimicrobial resistance in Escherichia coli and Pseudomonas aeruginosa from Intensive Care Units in The Netherlands, 1998-2005.Int J Antimicrob Agents 31:58-63.

[30] Goel N, Chaudhary U, Aggarwal R, Bala K (2009) Antibiotic sensitivity pattern of Gram negative bacilli isolated from the lower respiratory tract of ventilated patients in the Intensive care unit. Indian J Crit Care Med 13: 148-151.

[31] Brooke JS (2012) Stenotrophomonas maltophilia: an emerging global opportunistic pathogen. Clinical Microbiology Reviews $25(1): 2-41$

[32] Priyamvada R, Nishat HA, Indu B, Grover RK (2014): Antimicrobial Susceptibility Pattern of Burkholderia cepacia Isolates from Patients with Malignancy. J Glob Infect Dis 6(2): 90-91

[33] Šiširak M, Hukić M (2013) An outbreak of multidrug-resistant Serratia marcescens: The importance of continuous monitoring of nosocomial infections. Acta Medica Academica 42(1):25-31.

[34] Yang G, Benson R, Pelish T, Brown E, Winchell JM, Fields B (2010) Dual detection of Legionella pneumophila and Legionella species by real-time PCR targeting the $23 \mathrm{~S}-5 \mathrm{~S}$ rRNA gene spacer region. Clin Microbiol Infect 16: 255-261.

[35] Murdoch DR (2003) Diagnosis of Legionella infection. Clin Infect Dis 36: 64-9.

[36] 36-O'Neill E, Humphreys H (2005) Surveillance of hospital water and primary prevention of nosocomial legionellosis: what is the evidence? J Hosp Infect 59: 273-279.

[37] Qasem JA, Mustafa AS, Khan ZU (2008) legionella in clinical specimens and hospital water supply facilities: molecular detection and genotyping of the isolates. Med Princ Pract 17:49-55. 
[38] Salem MM, Muharram M, Alhosiny IM (2010) Distribution of Classes 1 and 2 Integrons among multi drug resistant E. coli isolated from hospitalized patients with urinary tract infection in Cairo, Egypt. Australian Journal of Basic and Applied Sciences 4:398-407.

[39] Sahuquillo-Arce JM, Selva M, Perpiña'n H, Gobernado M, Armero C, López-Quílez A, González F, Vanaclocha H (2011) Antimicrobial resistance in more than 100,000 Escherichia coli isolates according to culture site and patient age, gender, and location. Antimicrob Agents Chemother 55:1222-1228.

[40] Gafter-Gvili A, Paul M, Fraser A, Leibovici L (2007) Effect of quionolone prophylaxis in afebrile neutropenic patients on microbial resistance: systematic review and meta-analysis. J Antimicrob Chemother 59: 5-22.

[41] Freifeld AG, Bow EJ, Sepkowitz KA, Boeckh MJ, Ito JI., Mullen CA, Raad II, Kenneth V, Rolston KV, Young JH, Wingard JR (2011) Clinical practice guidelines for the use of antimicrobial agents in neutropenic patients with cancer: 2010 update by the Infectious Diseases Society of America. Clin Infect Dis 52: e56-e93.

[42] Jadhav S, Misra R, Gandham N, Ujagare M, Ghosh P, Angadi K Vyawahare C (2012) Increasing Incidence of Multidrug Resistance Klebsiella Pneumoniae Infections In Hospital And Community Settings. Inter J Microbiol. Res 4 (6): 253-257.
[43] El-Kholy A, Baseem H, Hall GS, Procop GW, Longworth DL (2003) Antimicrobial resistance in Cairo, Egypt 1999-2000: A survey of five hospitals. J Antimicrob Chemother 51: 625-630.

[44] Aeschlimann J (2003) The role of multidrug efflux pumps in the antibiotic resistance of Pseudomonas aeruginosa and other gram-negative bacteria. Pharmacotherapy 23(7): 916-924.

[45] Saied GM (2006) Microbial pattern and antimicrobial resistance, a surgeon's perspective: retrospective study in surgical wards and seven intensive-care units in two university hospitals in Cairo, Egypt. Dermatology 212(Suppl 1):8-14.

[46] Oliveira AL, Souza M, Carvalho-Dias VM, Ruiz MA, Silla L, Tanaka PY, Simões P, Trabasso P, Seber A, Lotfi CJ, Zanichelli MA, Araujo VR, Godoy C, Maiolino A, Urakawa P, Cunha CA, de Souza CA, Pasquini R, Nucci M (2007) Epidemiology of bacteremia and factors associated with multidrug-resistant Gram-negative bacteremia in hematopoietic stem cell transplant recipients. Bone Marrow Transplant 39: 775-781.

[47] Gudiol C, Tubau F, Calatayud L, Garcia-Vidal C, Cisnal M, Sánchez-Ortega I, Duarte R, Calvo M, Carratalà J (2011) Bacteraemia due to multidrug resistant gram-negative bacilli in cancer patients: risk factors, antibiotic therapy and outcomes. J Antimicrob Chemother 66: 657- 663. 